\title{
Harran Ovası Koşullarında Yazlık Aspir Bitkisinde Sulamanın Verim ve Yağ Kalitesi Üzerine Etkileri
}

\author{
*Abdullah Suat NACAR ${ }^{1}$ Veli DEĞIRMENCi ${ }^{1}$ Halil HATIPOĞLU1 Meral TAŞ$^{1}$ \\ Hüseyin ARSLAN ${ }^{2}$ Ahmet ÇIKMAN ${ }^{1}$ Abdullah ŞAKAK ${ }^{1}$ \\ ${ }^{1}$ GAP Tarımsal Araştırma Enstitüsü Müdürlüğü, Şanlıurfa \\ ${ }^{2}$ Siirt Üniversitesi, Ziraat Fakültesi, Tarla Bitkileri Bölümü, Siirt \\ *Sorumlu yazar e-posta (Corresponding author e-mail): asnacar@hotmail.com
}

Öz

Bu araştırma, Harran Ovası koşullarında farklı dönemlerde yapılan sulama uygulamalarının aspir bitkisinin verimi ve ürün kalitesi üzerine etkisini belirlemek ve araştırma bölgesinde yetiştirilen aspir bitkisi için uygun sulama programını belirlemek amacıyla, GAP Tarımsal Araştırma Enstitüsü tarafından Koruklu Merkez ve Koruklu Talat Demirören Araştırma İstasyonu arazisinde 2010-2012 yılları arasında yürütülmüştür. Deneme konuları; S1-Susuz, S2- Sapa kalkma döneminde 1 su, S3- Çiçeklenme öncesi 1 su, S4- Tohum bağlama devresinde 1 su, S5-Sapa kalkma döneminde 1 su + Çiçeklenme öncesi 1 su, S6- Sapa kalkma döneminde $1 \mathrm{su}+$ tohum bağlama devresinde $1 \mathrm{su}, \mathrm{S} 7$ - Çiçeklenme öncesi $1 \mathrm{su}+$ tohum bağlama devresinde $1 \mathrm{su}, \mathrm{S} 8-$ Sapa kalkma döneminde 1 su + Çiçeklenme öncesi 1 su + tohum bağlama devresinde 1 su S9- S8 konusuna uygulanacak sulamaların \%50'sinin uygulanması konularından oluşmuştur. Elde edilen araştırma sonuçları değerlendirildiğinde; Yazlık ekimlerde sulama konuları arasında istatistiki anlamda fark elde edilmiş ve yapılan değerlendirmeler sonucunda her 3 dönemde sulamanın yapıldığı S8 (tam su) konusu önerilmiştir. Ayrıca suyun kısıtlı olması durumunda her 3 dönemde hesaplanan suyun yarısının uygulandığı S9 konusu da önerilebilir. Önerilen konunun su tüketimi 460 mm, uygulanan sulama suyu miktarı ise 367.5 mm'dir. Aylık maksimum su tüketimi ise $160 \mathrm{~mm}$ ile haziran ayında gerçekleşmiştir.

Anahtar Kelimeler: Aspir, sulama, Harran ovası

\section{Effects of Irrigation on Yield and Yield Components at Safflower Plant in Harran Plain Condition}

\begin{abstract}
This research is determined effects of irrigations at different periods on water-yield relationships the quality and irrigation programme of winter and summer safflower at Koruklu Central and Koruklu Talat Demirören Research Stations of GAP Agricultural Research Institute between the years 2010-2012 for Harran Plain conditions. Irrigation subjects S1- no irrigation, S2- irrigation in vegetative period, S3- irrigation in flowering period , S4- irrigation in yield formation period, S5- irrigation in vegetative period + irrigation in flowering period S6- irrigation in vegetative period + irrigation in yield formation period, S7- irrigation in flowering period + irrigation in yield formation period, S8- irrigation in vegetative period + - irrigation in flowering period + irrigation in yield formation period, $S 9-50 \%$ of irrigation amount to be applied to $S 8$ subject. As a result, yields have been statistically significant difference at summer safflower. Since S8 subject which irrigated at all three period is recommended. Also in case of shortage of water S9 subject is suggested half of the water applied to the subject S8 In all three periods. The water consumption of the suggested subject was $460 \mathrm{~mm}$, the amount of applied irrigation is $367.5 \mathrm{~mm}$. Monthly maximum water consumption was $160 \mathrm{~mm}$ was in June.
\end{abstract}

Keywords: Safflower, irrigation, Harran plain 


\section{Giriş}

A spir, genellikle $50-150 \mathrm{~cm}$ arasında boylanabilen, dikenli ve dikensiz formları olan, dikenli formların dikensizlere göre daha fazla yağ içerdiği, sarı, beyaz, krem, kırmızı ve turuncu gibi değişik renklerde çiçeklere sahip, tohumları, beyaz, kahverengi ve üzerinde koyu çizgiler bulunan beyaz taneler şeklinde olan (ender durumlarda siyah tohumlara da rastlanabilir), dallanan ve her dalın ucunda içerisinde tohumları bulunan küçük tablalar oluşturan, renkli çiçekleri (petal) gıda ve kumaş boyasında kullanılan, derinlere gidebilen bir kazık kök sistemine sahip, tohumlarında \% 3040 arasında yağ bulunan, Linoleik (Omega-6) ve Oleik (Omega-9, zeytin yağı kalitesinde) olmak üzere 2 ayrı tipi olan, yağı yemeklik olarak kaliteli, biodizel yapımında da kullanılabilen, küspesi hayvan yemi olarak değerlendirilen, kuraklığa dayanıklı, yazlık karakterde ve ortalama 110-140 gün arasında yetişebilen tek yıllık bir uzun gün yağ bitkisidir.

Dünya'da 2012 yılı verilerine göre aspir ekim alanı 812195 ha olup, 780677 ton üretim ve $96.11 \mathrm{~kg} / \mathrm{da}$ tohum verimi olarak gerçekleşmiştir (Anonim 2013c). Ülkemizde 2012 yılı verilerine göre aspir ekim alanı 155.898 da olup, 19.945 ton üretim ve tohum verimi $128 \mathrm{~kg} / \mathrm{da}$ 'dır. Türkiye'de Güneydoğu Anadolu Bölgesinin aspir ekiliş alanı ise $33.631 \mathrm{da}$, üretimi 2890 ton ve tohum verimi $86 \mathrm{~kg} / \mathrm{da}$ 'dır. Şanlıurfa ilinde 33.625 da alanda aspir ekimi yapılmış, 2.889 ton tohum üretimi ve $86 \mathrm{~kg} / \mathrm{da}$ tohum verimi gerçekleştirilmiştir (Anonim 2013a).

Yağ bitkilerinin ve dolayısıyla aspir üretim alanlarının artırılmasında GAP'a dahil illerde büyük bir potansiyel oluşturmaktadır. Proje tamamlandığında 1.7 milyon hektar tarım alanı içerisinde bulunmaktadır. Harran Ovası'nda 369.264 hektarlık alan sulamaya açıımıştır. Sulu tarım yapılabilecek bu kadar geniş bir alan içerisinde aspir tarımının geliştirilmesi bölge ve ülke ekonomisi için önemli bir gelir kaynağını da beraberinde getirecektir.

Tarımda kalkınmanın temeli; yeterli su ve toprak potansiyelinin varlığına ve bunların uygun kullanma biçimine bağlıdır. Bu perspektiften Güneydoğu Anadolu Projesine (GAP) bakıldığında mevcut potansiyel ve gelecekteki projeksiyonda bölgenin su, toprak ve klimatolojik verilerinin son derece uygun olduğu görülmektedir.Uyum projesi olmayan sulama planlamalarında kısa sürede topraklarda tuzlanma ve alkalileşme meydana gelir. Birim alandan kalite ve kantite yönünden yüksek ürün alınması bir çok agronomik aktiviteler yanında uygun sulama yöntemlerinin seçilmesi ile olasıdır. Bu nedenle, her mikroklima ve bitki türü için uygun sulama aralığı ve sulama suyu miktarlarının saptanması gerekmektedir. Harran Ovasında bugün de mevcut olan ve gelecekte de önemli bir sorun olarak karşılaşabileceğimiz aşırı sulama sonucu oluşabilen tuzluluk ve taban suyu problemine önlem olabilecek daha az ve ölçülü su uygulaması yapılabilen basınçı sulama yöntemleri gittikçe daha önem kazanacak ve uygulama alanı bulacaktır.

Çalışmada, farklı dönemlerde yapılan sulama uygulamalarının aspir bitkisinin verimi ile ürün kalitesine etkilerinin belirlenmesi ve araştırma bölgesinde yapılan aspir yetiştiriciliğinde uygulanabilir sulama programlarının oluşturulması amaçlanmıştır. Yapılan araştırma ile ayrıca, bölgeye adapte olan tarla bitkilerinden, sebze tür ve çeşitlerden alternatif bitki oluşturarak bölge ve ulus yararına olacak agronomik çalışmalara katkıda bulunmak da amaçlanmıştır.

\section{Materyal ve Yöntem}

Araştırma, Harran Ovasında bulunan GAP Tarımsal Araştırma Enstitüsünün KorukluMerkez Işletme ve Talat Demirören Araştırma İstasyonlarında yürütülmüştür. Araştırma bölgede geniş alan içeren Harran toprak serisinde yapılmıştır. Bu seri toprakları, Harran Ovasını doğu, batı ve kuzeyden çevreleyen Tektek, Fatik ve Urfa Dağlarından gelen çamur akıntılarından oluşmuş, alüviyal ana materyalli, düz ve düze yakın eğimli, derin topraklardır. Tipik kırmızı profilleri killi bünyelidir. Tüm profil çok kireçlidir ve aşağılara doğru artan yoğunlukta kireç ceplerini içermektedir. A,B,C horizonlu topraklar olup, $\mathrm{pH} 7.3$ ile 7.8 arasında, organik madde içeriği düşük, katyon değişim kapasitesi kil içeriğine bağı olarak alt katmanlara doğru artmaktadır (Dinç ve ark. 1988). Ova topraklarının infiltrasyon hızları genellikle yüksektir (12-116 $\mathrm{mm} / \mathrm{h})$. Araştırmanın yürütüldüğü deneme istasyonun infiltrasyon hızı ise ortalama $48 \mathrm{~mm} / \mathrm{h}$ (Karaata, 1991). 
Şanlıurfa, Güneydoğu Anadolu iklim bölgesine dahil olmakla beraber, Akdeniz ikliminin etkisi altındadır, Yazları sıcak ve kurak kışları ise ılık olan bir iklim özelliği göstermektedir, Güneyden kuzeye ve batıdan doğuya gittikçe yağış miktarları artmaktadır. Çalışmanın yapıldığı Araştırma Enstitüsünün Koruklu İstasyonuna ait 24 yıllık rasat değerlerine göre, yıllık toplam yağış $365.2 \mathrm{~mm}$ olup, yıllık ortalama sıcaklık $17.2^{\circ} \mathrm{C}$, en yüksek sıcaklık $46.8^{\circ} \mathrm{C}$. en düşük sıcaklık ise $-16.8^{\circ} \mathrm{C}$ dir. Yıllık ortalama oransal nem \%51, yıllık buharlaşma toplamı ise $1848.8 \mathrm{~mm}$ ' dir (Anonim 2003). Araştırmanın yürütüldüğü yıllarda vejetasyon periyodu boyunca 2010 yılında 202.3 mm, 2011 yılında 222.50 mm 2012 yılında ise $295.1 \mathrm{~mm}$ yağış olmuştur. Aylık maksimum sıcaklıklar $11^{\circ} \mathrm{C}-43.2^{\circ} \mathrm{C}$ arasında değişirken minimum sıcaklıklar $-7.120 .4^{\circ} \mathrm{C}$ arasında değişmiştir (Anonim 2012).

Denemede, Remzibey-05 aspir çeşidi bitki materyali olarak kullanılmıştır. Çeşidin Çiçek rengi sarı, tane rengi ise beyaz ve dikenli bir yapıya sahiptir. Bitki boyu $50-150 \mathrm{~cm}$ arasındadır. Remzibey 05 Erkenci bir çeşit olup, Yazlık tabiatlı ve kuru tarım alanları için önerilir. Sulama ile daha yüksek verim verir. Verim düzeyi kışlık ekimlerde $300-500$ kg/da , Yazlık ekimlerde 80-250 kg/da'a ulaşır. Sulama ile tarımı yapıldığı alanlarda gübrenin verime etkisi yüksektir.Remzibey - 05'in bin dane ağırlığı 46$50 \mathrm{~g}$, kabuk oranı $\% 40$, protein oranı $\% 14$ ve yağ oranı ise \%35-40'dır. Çeşide ait yağ asitleri komposizyonlarına bakıldığında oleik asit miktarı \%69.5, linoleik asit miktarı ise \% 21.4'dir. Oleik asidin yüksek oranda olması zeytinyağı özelliğine yakın yağ olduğunu gösterir (Anonim 2011)

Sulama suyu araştırmanın yürütüldüğü kanal suyundan sağlanmıştır. Kontrol biriminden geçen su ana boru hattı ile deneme alanına gelmektedir. Sulama suyu, ana boru hattına bağlanan borular yardımıyla parsel başlarına getirilmiş ve sulamalar deneme bloklarına paralel olarak yerleştirilen $75 \mathrm{~mm}$ dış çaplı sulama boruları ile gerçekleştirilmiştir. Araştırmada kullanılan sulama sularının kimyasal özellikleri Çizelge 1' de verilmiştir. Deneme tesadüf blokları deneme deseninde 3 tekrarlamalı olarak kışlık ve yazlık olmak üzere 2 ayrı deneme şeklinde yürütülmüştür. Ekimde parsel ölçüleri : $2.40 \mathrm{~m} \times 9.00 \mathrm{~m}=21.60 \mathrm{~m}^{2}$, hasatta : $2.0 \mathrm{~m} \times 8.00 \mathrm{~m}=16.0 \mathrm{~m}^{2}$. Sıra üzeri : 8-10 cm, sıra arası: $20 \mathrm{~cm}$ olarak alınmıştır. Deneme parselleri arasında ve bloklar arasında $3.0 \mathrm{~m}$ genişliğinde tampon alanlar bırakılmıştır.

Yanlardan 60'ar cm, parsel baş ve sonlarından da 1'er m kenar tesiri olarak kabul edilmiş ve hesaplamaya dahil edilmemiştir.

\section{Sulama Konuları}

Araştırmada bitkinin farklı gelişme dönemlerine göre sulama uygulamaları yapılmış ve konular;

Çizelge 1. Araştırmada kullanılan sulama sularının bazı kimyasal özellikleri

Table 1. Some chemical propertios of irrigation water used in this research

\begin{tabular}{|c|c|c|c|c|c|c|c|c|c|c|c|c|c|}
\hline \multirow{2}{*}{$\begin{array}{c}\mathrm{EC} \\
\mu \mathrm{S} / \mathrm{m}\end{array}$} & \multicolumn{4}{|c|}{ Katyonlar (me/L) } & \multicolumn{5}{|c|}{ Anyonlar (me/L) } & \multirow[t]{2}{*}{$\mathrm{pH}$} & \multirow[t]{2}{*}{ SAR } & \multicolumn{2}{|r|}{ Sinıf } \\
\hline & $\mathrm{Na}$ & $\mathrm{K}$ & $\begin{array}{l}\mathrm{Ca}+ \\
\mathrm{Mg}\end{array}$ & $\begin{array}{c}\text { Top. } \\
\text { katyon }\end{array}$ & $\mathrm{CO}_{3}$ & $\mathrm{HCO}_{3}$ & $\mathrm{Cl}$ & $\mathrm{SO}_{4}$ & $\begin{array}{c}\text { Top. } \\
\text { Anyon }\end{array}$ & & & Bor & \\
\hline 354 & 0.08 & 0.02 & 3.2 & 3.3 & - & 1.9 & 1.1 & 0.3 & 3.3 & 7.45 & 0.06 & - & $\mathrm{T}_{2} \mathrm{~A}_{1}$ \\
\hline
\end{tabular}

Çizelge 2. Deneme alanı topraklarının bazı fiziksel ve kimyasal özellikleri Table 2: Some physical and chemical properties of experimental area

\begin{tabular}{|c|c|c|c|c|c|c|c|c|c|c|c|}
\hline & $\begin{array}{c}\text { Derinlik } \\
\text { (cm) }\end{array}$ & $\begin{array}{l}\text { Bünye } \\
\text { Sınıfı }\end{array}$ & $\begin{array}{l}\text { TK } \\
(\%)\end{array}$ & $\begin{array}{l}\text { SN } \\
(\%)\end{array}$ & $\begin{array}{l}\text { Hacim } \\
\text { ağırlığı } \\
\left(\mathrm{g} / \mathrm{cm}^{3}\right)\end{array}$ & $\begin{array}{c}\text { Tuz } \\
\text { (dS/m) }\end{array}$ & $\mathrm{pH}$ & $\begin{array}{c}\text { Kireç } \\
(\mathrm{CaC} \\
\left.\mathrm{O}_{3}\right) \\
(\%)\end{array}$ & $\begin{array}{l}\text { Fosfor } \\
\left(\mathrm{P}_{2} \mathrm{O}_{5}\right) \\
(\mathrm{kg} / \mathrm{da})^{*}\end{array}$ & $\begin{array}{c}\text { Potasyum } \\
\left(\mathrm{K}_{2} \mathrm{O}\right) \\
(\mathrm{kg} / \mathrm{da})^{\star}\end{array}$ & $\begin{array}{l}\text { Org. } \\
\text { madde } \\
(\%)^{*}\end{array}$ \\
\hline \multirow{3}{*}{ 응 } & $0-30$ & C & 29.01 & 20.43 & 1.32 & 1.02 & 7.45 & 20.5 & 2.81 & 119.60 & 1.24 \\
\hline & $30-60$ & C & 27.36 & 20.47 & 1.37 & 1.09 & 7.46 & 20.0 & & & \\
\hline & $60-90$ & C & 29.01 & 21.11 & 1.37 & 1.22 & 7.40 & 19.6 & & & \\
\hline \multirow{3}{*}{$\stackrel{N}{\grave{N}}$} & $0-30$ & C & 33.44 & 21.64 & 1.25 & 0.97 & 7.72 & 31.1 & 3.71 & 111.90 & 2.04 \\
\hline & $30-60$ & C & 32.34 & 21.99 & 1.30 & 0.87 & 7.77 & 25.4 & & & \\
\hline & $60-90$ & C & 34.38 & 22.75 & 1.35 & 0.96 & 7.74 & 24.3 & & & \\
\hline
\end{tabular}


S1-Susuz, S2- Sapa kalkma döneminde 1 su, S3- Çiçeklenme öncesi 1 su, S4- Tohum bağlama devresinde 1 su, S5-Sapa kalkma döneminde 1 su + Çiçeklenme öncesi 1 su, S6Sapa kalkma döneminde 1 su + tohum bağlama devresinde 1 su , S7- Çiçeklenme öncesi 1 su + tohum bağlama devresinde 1 su, S8- Sapa kalkma döneminde 1 su+Çiçeklenme öncesi 1 su+tohum bağlama devresinde 1 su S9- S8 konusuna uygulanacak sulamaların \%50'sinin uygulanması şeklindedir.

\section{Bitki su tüketimi ve sulama suyunun hesaplanması}

Deneme süresince ekimde, her sulamadan önce ve hasatta orta tekerrürdeki parsellerin 0$30,30-60$ ve $60-90 \mathrm{~cm}$ toprak katmanlarından toprak örnekleri alınarak, gravimetrik yöntemle topraktaki mevcut nem düzeyi belirlenmiştir. Sulamalarda parsellere, toprak profilinin $90 \mathrm{~cm}$ derinliğindeki eksik nemi tarla kapasitesine getirecek miktarda sulama suyu su saatinden geçirilerek ölçülü olarak verilmiştir. Bitki su tüketimi su dengesi eşitliğine dayanan " $\mathrm{Nem}$ Azalma Yöntemi” ile hesaplanmıştır. (Beyce ve ark. 1972).

$\mathrm{I}=\mathrm{QfC}-\mathrm{Qc}$

$Q_{c}=$ Sulamadan önceki mevcut nem $(\mathrm{mm})$

Qfc = Tarla kapasitesi $(\mathrm{mm})$

Aspir ekimi için ön bitkinin hasadından hemen sonra tarla pullukla derin olarak, ekimden önce ise kültivatörle yüzlek olarak işlenmiştir. Daha sonra floatla tesviye yapılarak tohum yatağı hazırlanmıştır. Kışlık ekimler ekim sonu- kasım ayı başlarında, yazlık ekimler ise şubat - mart aylarında ekim derinliği, $4-5 \mathrm{~cm}$ olacak şekilde ekilmiş ve çıkışları sağlanmıştır. Ekim sırasında dekara $5 \mathrm{~kg}$. saf olarak azot, ve $5 \mathrm{~kg} / \mathrm{da} \mathrm{P}_{2} \mathrm{O}_{5}$ 20-20 kompoze gübre formunda verilmiştir. Aspir çıkışlarının tamamlanmasından sonra seyreltme yapılmıştır. Yeşil kurt'a karşı ilaçlı mücadele yapılmıştır. Hasat, yaprakların büyük bir bölümünün tamamen kuruduğu (kahverengileştiği), çiçek çanak yapraklarının kahverengiye döndüğü ve tanelerin tamamen beyaz renk aldığı dönemde yapılmıştır. Araştırmada yıllara göre fenolojik gözlem ve bazı tarımsal işlemlerle ilgili tarihler Çizelge 3'de verilmiştir.

\section{Bulgular ve Tartışma}

\section{Sulama Konularının Aspir Verimine Etkisi}

Yazlık denemede ise 2010 yılında çıkışlardaki problem nedeniyle ekim yenilenmek zorunda kalınmış, normale göre 1 aylık gecikmeye neden olmuştur. 2010 yılında hem istatistiki farklılık olmaması ve verim değerlerinin diğer 2 yıldan çok farklı olmasından dolayı değerlendirme dışı bırakılmıştır. 2011 ve 2012 yıllarında istatistiki olarak 0.01 önemlilik düzeyinde farklılık elde edilmiştir. Yıllara göre elde edilen yazlık aspir verimlerinin toplu analizinin yapılıp yapılamayacağı Khi-kare (Hesaplanan $X^{2}=2.06$,

Çizelge 3. Araştırma yıllarında yapılan bazı işlem ve gözlem tarihleri

Table 3. Dates of some observations and applications on following years

\begin{tabular}{llll}
\hline Gözlemler & Yazlık & & \\
& 2010 & 2011 & 2012 \\
\hline Ekim & 10.04 .2010 & 09.03 .2011 & 14.03 .2012 \\
Çıkış & 21.04 .2010 & 21.03 .2011 & 27.03 .2012 \\
Sapa kalkma & 01.06 .2010 & 10.05 .2011 & 08.05 .2012 \\
Çiçeklenme & 11.06 .2010 & 14.06 .2011 & 07.06 .2012 \\
Tohum bağlama & 28.06 .2010 & 28.06 .2011 & 25.06 .2012 \\
Hasat & 01.08 .2010 & 20.07 .2011 & 16.07 .2012 \\
\hline
\end{tabular}

Çizelge 4. Deneme yıllarında yazlık aspirde konuların ortalama verimleri (kg/da)

Table 4. Average yields of spring safflower on following years ( $\mathrm{kg} / \mathrm{da}$ )

\begin{tabular}{cccccccccc}
\hline & & \multicolumn{9}{c}{ Konular } \\
Yıllar & $\mathrm{S} 1$ & $\mathrm{~S} 2$ & $\mathrm{~S} 3$ & $\mathrm{~S} 4$ & $\mathrm{~S} 5$ & $\mathrm{~S} 6$ & $\mathrm{~S} 7$ & $\mathrm{~S} 8$ & $\mathrm{~S} 9$ \\
\hline 2011 & $149.16 \mathrm{c}$ & $174.16 \mathrm{bc}$ & 176.87 & 159.47 & 183.0 & 191.76 & 187.81 & 228.01 & 213.8 \\
& & & $\mathrm{abc}$ & $\mathrm{c}$ & $1 \mathrm{abc}$ & $\mathrm{abc}$ & $\mathrm{abc}$ & $\mathrm{a}$ & $5 \mathrm{ab}$ \\
2012 & 126.98 & $192.08 \mathrm{ab}$ & 154.38 & 129.48 & 210.4 & 177.40 & 159.38 & 216.67 & 197.5 \\
& $\mathrm{e}$ & $\mathrm{c}$ & $\mathrm{de}$ & $\mathrm{e}$ & $2 \mathrm{ab}$ & $\mathrm{bcd}$ & $\mathrm{cde}$ & $\mathrm{a}$ & $0 \mathrm{ab}$ \\
Ort & 138.07 & $183.12 \mathrm{bc}$ & 165.62 & 144.47 & 196.7 & 184.58 & 1773.5 & 222.74 & 205.6 \\
& $\mathrm{e}$ & $\mathrm{d}$ & $\mathrm{de}$ & $\mathrm{e}$ & $1 \mathrm{abc}$ & $\mathrm{bcd}$ & 9cd & $\mathrm{a}$ & $7 \mathrm{ab}$ \\
\hline
\end{tabular}


$\mathrm{SD}=1$ den Çizelge $\mathrm{X}^{2}$ değerleri \%5 için 3.84 ve $\% 1$ için 6.63) homojenlik testine göre kontrol edilmiştir. Yıllara göre hata varyansların homojen olduğu görülmüştür. Bunun sonucu olarak iki yıllık verilerin toplu varyans analizi yapılmıştır Toplu varyans analiz sonuçlarına göre, yıllar ve su uygulamaları arasında 0.01 hata seviyesinde fark bulunmuş, yıl x konu interaksiyonunun önemli olmaması nedeniyle deneme konuları toplu olarak değerlendirilmiştir. 2011-2012 toplu varyans analizde 2 yıllık ortalama verim değerlerine bakıldığında en yüksek verimin $222.74 \mathrm{~kg} / \mathrm{da}$ ile S8 (tam su) konusundan en düşük veriminde $138.07 \mathrm{~kg} / \mathrm{da} \mathrm{S} 1$ (susuz) konusundan elde edildiği görülmektedir. Yapılan Duncan testinde S8 konusu I.grupta, S9 konusu II.grupta, S5 konusu III.grupta, S6 ve S2 konuları IV.grupta, S7 konusu V. grupta, S3 konusu VI. grupta, S4 ve S1 konuları ise VII.gruba girmişlerdir.

Çizelge 5. Yazlık aspirde konulara uygulanan yıllık toplam sulama suyu miktarları $(\mathrm{mm})$ Table 5. Total annual irrigation $(\mathrm{mm})$ applied on spring safflower on different subjects

\begin{tabular}{|c|c|c|c|c|c|c|c|c|c|}
\hline Yıllar & $\begin{array}{l}\text { KoI } \\
\text { S1 }\end{array}$ & S2 & S3 & S4 & S5 & S6 & S7 & S8 & S9 \\
\hline 2011 & 27 & 124 & 144 & 160 & 238 & 274 & 264 & 336 & 168 \\
\hline 2012 & 25 & 155 & 181 & 186 & 256 & 316 & 277 & 347 & 175 \\
\hline Ort & 26 & 165.5 & 188.5 & 199.0 & 273.0 & 321.0 & 296.5 & 367.5 & 197.5 \\
\hline
\end{tabular}

Çizelge 6 Yazlık aspirde konuların mevsimlik su tüketimleri ( $\mathrm{mm}$ )

Table 6. Water consumption of spring safflower on different subjects $(\mathrm{mm})$

\begin{tabular}{|c|c|c|c|c|c|c|c|c|c|}
\hline Yillar & $\begin{array}{l}\text { Kon } \\
\text { S1 }\end{array}$ & S2 & S3 & S4 & S5 & S6 & S7 & S8 & S9 \\
\hline 2011 & 207 & 311 & 301 & 302 & 388 & 376 & 356 & 423 & 305 \\
\hline 2012 & 197 & 342 & 328 & 333 & 364 & 389 & 412 & 497 & 345 \\
\hline Ort & 202 & 326.5 & 314.5 & 317.5 & 376 & 382.5 & 384 & 460 & 325 \\
\hline
\end{tabular}

Çizelge 7. Yazlık aspir kalitesi ve bitki gelişimi ile ilgili analiz değerleri

Table 7. Analysis results for spring safflower quality and plant development

\begin{tabular}{|c|c|c|c|c|c|c|c|c|c|c|}
\hline & & \multicolumn{9}{|c|}{ Konular } \\
\hline & Yıllar & S1 & $\mathrm{S} 2$ & S3 & S4 & S5 & S6 & S7 & S8 & s9 \\
\hline \multirow{3}{*}{ Bitki boyu (cm) } & 2011 & 76.7 & 77.0 & 77.0 & 75.7 & 83.3 & 87.3 & 76.7 & 82.3 & 76.7 \\
\hline & 2012 & 55.7 & 61.3 & 52.5 & 58.8 & 63.4 & 62.5 & 57.7 & 61.4 & 63.0 \\
\hline & Ort & 66.2 & 69.2 & 64.8 & 67.3 & 73.4 & 74.9 & 67.2 & 71.9 & 69.9 \\
\hline \multirow{3}{*}{ Bindane ağ. (gr) } & $2011^{* *}$ & $33.38 \mathrm{~cd}$ & $33.15 \mathrm{~cd}$ & $33.48 \mathrm{bcd}$ & $33.16 \mathrm{~cd}$ & $35.04 \mathrm{a}$ & $34.43 a b c$ & $32.63 \mathrm{~d}$ & $34.83 a b$ & $33.98 a-d$ \\
\hline & $2012^{\star *}$ & $33.58 b$ & $32.78 b$ & $33.35 b$ & $32.92 b$ & $34.26 a b$ & $34.47 a b$ & $32.91 b$ & $35.87 a$ & $34.18 a b$ \\
\hline & Ort & 33.5 & 33.0 & 33.4 & 33.0 & 34.7 & 34.5 & 32.8 & 35.4 & 34.1 \\
\hline \multirow{3}{*}{ Yandal sayısı (adet) } & 2011 & 7.13 & 6.86 & 7.86 & 8.13 & 7.46 & 7.73 & 7.00 & 8.40 & 7.06 \\
\hline & 2012 & 6.40 & 7.07 & 6.60 & 7.00 & 6.73 & 7.13 & 6.40 & 7.07 & 6.60 \\
\hline & Ort & 6.77 & 6.97 & 7.23 & 7.57 & 7.10 & 7.43 & 6.70 & 7.74 & 6.83 \\
\hline \multirow{3}{*}{ Tabla çapı (mm) } & 2011 & 19.86 & 19.23 & 18.76 & 19.03 & 20.50 & 19.50 & 19.23 & 19.63 & 19.03 \\
\hline & 2012 & 22.09 & 22.91 & 23.12 & 23.16 & 23.31 & 24.65 & 22.91 & 23.23 & 22.84 \\
\hline & Ort & 20.98 & 21.07 & 20.94 & 21.50 & 21.91 & 22.08 & 21.07 & 21.43 & 20.94 \\
\hline \multirow{3}{*}{ Tabla sayısı (ad.) } & 2011 & 16.33 & 14.73 & 15.13 & 17.40 & 18.93 & 18.13 & 15.60 & 19.33 & 17.20 \\
\hline & 2012 & 21.40 & 21.40 & 19.60 & 18.27 & 17.47 & 21.87 & 18.53 & 21.87 & 18.00 \\
\hline & Ort & 18.87 & 18.07 & 17.37 & 17.84 & 18.20 & 20.00 & 17.07 & 20.60 & 17.60 \\
\hline \multirow{3}{*}{ Yağ Oranı (\%) } & 2011 & 28.73 & 27.84 & 27.13 & 27.34 & 30.28 & 29.13 & 27.40 & 30.17 & 27.38 \\
\hline & 2012 & 31.47 & 29.20 & 27.95 & 30.80 & 27.96 & 31.99 & 30.51 & 29.81 & 31.51 \\
\hline & Ort & 30.10 & 28.52 & 27.54 & 29.07 & 29.12 & 30.56 & 28.96 & 29.99 & 29.45 \\
\hline \multirow{3}{*}{ Protein oranı (\%) } & 2011 & 19.41 & 19.93 & 18.99 & 20.29 & 20.35 & 19.37 & 21.54 & 19.22 & 21.35 \\
\hline & 2012 & 17.51 & 17.60 & 20.31 & 18.34 & 18.16 & 17.89 & 18.56 & 19.91 & \multirow{2}{*}{$\begin{array}{l}18.18 \\
19.77\end{array}$} \\
\hline & Ort & 18.46 & 18.77 & 19.65 & 19.32 & 19.26 & 18.63 & 20.05 & 19.57 & \\
\hline
\end{tabular}




\section{Sulama Suyu Miktarı ve Su Tüketimi}

Denemenin yürütüldüğü yıllarda konulara verilen sulama suyu miktarları çizelge 5 'de ve su tüketimi değerleri de çizelge 6 'da verilmiştir. Üç yıllık ortalama mevsimlik sulama suyu değerleri konulara göre 26- $367.5 \mathrm{~mm}$ arasında değişirken, ortalama mevsimlik su tüketim değerleri de sulama suyu değerleriyle bağlantılı olarak 202 - 460 mm arasında değişmiştir. En yüksek su tüketimleri sırasıyla S8, S7, S6, S5 ve 59 konularında olurken, sulama suyunun kısıtlanması ve topraktaki mevcut nemin zamanla kullanılması nedeniyle en düşük su tüketimleri $\mathrm{S} 1, \mathrm{~S} 2, \mathrm{~S} 3$ ve $\mathrm{S} 4$ konularında olmuştur.

\section{Aspir Kalitesi ve Bitki Gelişimi ile İlgili Bulgular}

Çizelge 7'nin incelenmesinden de anlaşılacağı üzere yazlık aspirde ise 2011 ve 2012 yıllarında bindane ağılıkları yapılan sulamalardan etkilenmiştir. Aspirde yağ oranları ortalama olarak \%27.54-\%30.56 arasında değişim göstermiştir. Bindane ağılıkları ortalama olarak 33-35.4 gr arasında değişim göstermiştir.

\section{Sonuç}

Araştrmadan elde edilen bu sonuçları esas alarak yapılan değerlendirmelerde Harran ovası koşullarında yapılan aspir yetiştirciliğinde;

- Ekim tarihleri verimi çok etkilediğinden dolayı hem kışlık ve hem de yazlık ekimlerde geç ekim yapılmamalıdır.

- Ekim döneminin kurak geçmesi durumunda imkan varsa çıkış için 20 - 30 mm'lik bir sulama yapılmalıdır.
- Yazlık ekimlerde sulama konuları arasında istatistiki anlamda farklar mevcut olduğundan, elde edilen bulgular değerlendirilerek her 3 dönemde sulamanın yapıldığı S8 (tam su) konusu önerilmektedir. Ayrıca suyun kısıtlı olması durumunda her 3 dönemde hesaplanan suyun yarısının uygulandığı S9 konusu da önerilebilir.

\section{Kaynaklar}

Anonim 2011. www.ataem.gov.tr/ (Erişim tarihi: 13.06.2011.)

Anonim 2012. Devlet Meteoroloji İşleri Genel Müdürlüğü, Şanlıurfa Meteoroloji Bölge Müdürlüğü, Akçakale İlçesi meteoroloji istasyonuna ait iklim değerleri:

Anonim .2013a. Bitkisel Üretim İstatistikleri, http://tuikapp.tuik.gov.tr/bitkiselapp/bitkisel.zul (Erişim tarihi: 13.06.2013.)

Beyce Ö., Madanoglu K., Ayla Ç., 1972. Türkiye'de yetiştirilen bazı sulanır mahsullerin su istihlakleri. Merkez Topraksu Araştırma Enstitüsü Yayınları Gn. Yayın No:15, Teknik yayın No:12 Ankara

Dinç U., Şenol S., Satın M., Kapur S., Güzel N., Derici R., Yeşilsoy M.Ş., Yeğingil İ., Sarı M. Kaya Z., Aydın M., Kettaş F., Berkman A., Çolak A.K., Yılmaz K., Tunçgöğüs B., Çavuşgil V., Özbek H., Gülüt K.Y., Kahraman C., Dinç O., Kara E.E., 1988. Güneydoğu Anadolu Toprakları (GAT), I.Harran Ovası, TÜBITAK, TOAG 534, Kesin Sonuç Raporu

Karaata H., 1991, Urfa-Harran Ovası Sulama Rehberi Köy Hizmetleri Şanlıurfa Araştırma Enstitüsü Yayınları, Genel Yayın No:10,Rapor Yayın No:8, Şanlıurfa 